\title{
The effect of a unilateral upper extremity load (backpack) on the resulting spinal posture
}

\author{
Patrick Knott ${ }^{*}$, Sarah Davis, Ashley Harrison, Carly Larson \\ From 10th International Conference on Conservative Management of Spinal Deformities - SOSORT 2013 \\ Annual Meeting \\ Chicago, IL, USA. 8-11 May 2013
}

\section{Background}

A frequent question from parents of adolescents is whether there are risk factors that could make a scoliosis curve increase, specifically whether carrying a heavy backpack on one shoulder could be detrimental to an existed curve. There has been very little research published to answer whether a unilateral upper extremity load would have an effect on spine position, let alone scoliosis progression (Chow, 2006).

\section{Purpose}

The purpose of this study was to measure changes in spinal curvature with increasing unilateral carrying load in order to analyze the possible risk for patients with adolescent scoliosis.

\section{Method}

Six young, non-scoliotic adults were measured with carrying loads of $15 \%$ and $20 \%$ of the subjects' body weight compared to the neutral condition and analyzed for significant change. The formetric 3-dimensional/4-dimensional topography scanner was used to measure (1) weight distribution (2) kyphotic angle of the thoracic spine (3) lordotic angle of the lumbar spine (4) scoliosis angle of either the thoracic or lumbar spine, (5) coronal vertical axis (6) sagittal axis, and (7) shoulder tilt.

\section{Results}

Coronal imbalance had a small shift of about $4 \mathrm{~mm}$ off center towards the side holding the backpack. Sagittal imbalance shifted forward by about $15 \mathrm{~mm}$, regardless of the side holding the backpack. The pelvic obliquity changed by about $2^{\circ}$ away from the side holding the backpack. Kyphosis and lordosis stayed fairly stable.
Shoulder slope changed by about $8^{\circ}$, with the backpack side lower, resulting in a $2 \mathrm{~mm}$ shoulder height difference. Weight shifted towards the side holding the backpack by about $20 \%$, but did not shift towards the front or back.

\section{Conclusions and discussion}

We found that coronal imbalance, sagittal imbalance, shoulder tilt and weight distribution changed significantly from the neutral position with $15 \%$ and $20 \%$ weight applied to either side of the body. Although it is not known what effect this would have on progression of scoliosis, these changes could potentially contribute in a negative way to spinal imbalance.

\section{Published: 18 September 2013}

\section{References}

1. Chow DH, et al: The effect of backpack weight on the standing posture and balance of schoolgirls with adolescent idiopathic scoliosis and normal controls. Gait Posture 2006, 24(2):173-181.

2. Chow DH, Ng XH, Holmes AD, Cheng JC, Yao FY, Wong MS: Effects of backpack loading on the pulmonary capacities of normal schoolgirls and those with adolescent idiopathic scoliosis. Spine 2005, 30(21): E649-E654.

3. Chow DH, Leung DS, Holmes AD: The effects of load carriage and bracing on the balance of schoolgirls with adolescent idiopathic scoliosis. Eur Spine J 2007, 16(9):1351-1358.

doi:10.1186/1748-7161-8-S2-O26

Cite this article as: Knott et al:: The effect of a unilateral upper

extremity load (backpack) on the resulting spinal posture. Scoliosis 2013 8(Suppl 2):O26.

* Correspondence: Patrick.Knott@RosalindFranklin.edu

Rosalind Franklin University of Medicine and Science, Chicago, USA

(c) 2013 Knott et al.; licensee BioMed Central Ltd. This is an Open Access article distributed under the terms of the Creative Commons 